\title{
Positional therapy in the management of positional obstructive sleep apnea-a review of the current literature
}

\section{Citation}

Omobomi, Olabimpe, and Stuart F. Quan. 2017. "Positional Therapy in the Management of Positional Obstructive Sleep Apnea-a Review of the Current Literature." Sleep and Breathing (August 29). doi:10.1007/s11325-017-1561-y.

\section{Published Version}

doi:10.1007/s11325-017-1561-y

\section{Permanent link}

http://nrs.harvard.edu/urn-3:HUL.InstRepos:35427798

\section{Terms of Use}

This article was downloaded from Harvard University's DASH repository, and is made available under the terms and conditions applicable to Open Access Policy Articles, as set forth at http:// nrs.harvard.edu/urn-3:HUL.InstRepos:dash.current.terms-of-use\#OAP

\section{Share Your Story}

The Harvard community has made this article openly available.

Please share how this access benefits you. Submit a story.

\section{Accessibility}


Positional Therapy in the Management of Positional Obstructive Sleep Apnea - a review of the current literature Olabimpe Omobomi MD, Stuart F Quan MD

Division of Sleep and Circadian Disorders, Brigham and Women's Hospital and Harvard Medical School, Boston, MA 02115

\section{Corresponding Author}

Olabimpe Omobomi MD

ORCID ID: 0000-0003-2394-5245

Division of Sleep and Circadian Disorders, Brigham and Women's Hospital and Harvard Medical School, Boston, MA

221 Longwood Avenue, Boston MA 02115

Tel: 6177324013

Email: oomobomi@bwh.harvard.edu

This manuscript has been seen and approved by all authors.

The authors have no conflicts of interest and did not receive any financial support related to this manuscript. 


\begin{abstract}
Purpose:

More than 50\% of Obstructive Sleep Apnea (OSA) patients have worsening of their OSA in the supine position (positional obstructive sleep apnea [POSA], commonly defined as supine to non-supine apnea hypopnea index (AHI) ratio of $\geq 2$ ). Positional Therapy (PT) aims to prevent patients from sleeping in the supine position. One of the major limiting factors to the routine use of PT in clinical practice is the lack of validated tools to measure compliance objectively. Furthermore, there are no universal guidelines to determine if PT will be effective as stand alone or as adjunctive therapy. This paper assesses recent literature on PT demonstrating its effectiveness in management of POSA. It also outlines the proposed subclassification systems for POSA.
\end{abstract}

Methods: Electronic literature review using EMBASE

Results:

Since the last review of PT by Ravesloot et al. (2012), ten studies were identified which demonstrate effectiveness of PT in POSA. We found three publications proposing different subclassification systems for POSA. There were three studies validating different compliance monitoring tools for PT. One study showed the cost benefits of incorporating PT into OSA management.

\title{
Conclusion:
}

Positional Therapy is an effective treatment for POSA and progress has been made in development of tools for measuring compliance. Creating a subclassification of POSA may help develop targeted therapy for patients and determine its use as stand alone or adjunct therapy. The integration of PT into POSA management may be cost effective when compared to the use of CPAP alone.

Keywords: Positional Therapy; Obstructive Sleep Apnea; Continuous Positive Airway Pressure 


\section{Introduction}

Continuous Positive Airway Pressure (CPAP) remains the first line of treatment for moderate to severe obstructive sleep apnea (OSA) [1, 2], but compliance with therapy is frequently poor [2, 3]. Mandibular advancement devices, upper airway stimulation, upper airway surgery, maxillofacial surgery and bariatric surgery are alternative options for management of OSA. Lifestyle modifications including weight loss, avoidance of alcohol, opioids and sedatives are also beneficial.

Given the increasing prevalence of obesity, we anticipate the prevalence of OSA will increase. Because of the limited therapeutic options, there is a need to fully incorporate more modalities into the treatment algorithm for OSA.

More than $50 \%$ of cases of OSA are worse or exist solely in certain positions, the so-called "worst sleeping position" which is typically apparent on polysomnographic monitoring. This is usually the supine position in the vast majority of cases $[4,5,6]$. Positional Therapy (PT) aims at preventing sleep in the supine position.

Positional OSA (POSA) is often defined as a supine to non-supine apnea hypopnea index (AHI) ratio of $\geq 2$. However this definition is not universally accepted. Although positional therapy has been shown to be an effective, conservative option for the management of POSA, it is not routinely used in clinical practice. One major limitation to the routine use of PT is the lack of a reliable tool for measurement of compliance as well as continued effectiveness.

Positional therapy alone may be adequate as the sole treatment modality for a subgroup of POSA patients who have sleep disordered breathing events only in the supine position or who have an insignificant number of events (defined as AHI $<5 /$ hour) in non supine positions. It may also be useful as adjunct therapy in POSA patients who have a significant number of events (AHI $>5$ /hour) but to a lesser degree outside of the supine position. Positional therapy may also serve as salvage therapy for patients with POSA who refuse all other modalities of treatment, by helping to reduce the severity of OSA[7].

Despite the documented efficacy of PT in the treatment of patients with POSA, it remains unclear which POSA patients may benefit from its long term use. It is not known whether some PT techniques are superior to others and whether it is cost effective therapy in the long term.

The last review article on PT done by Ravesloot et al [5] in 2012 concluded that PT is a simple, inexpensive treatment option for POSA. Despite the fact that the effectiveness of PT has been shown in prior research, its use in clinical practice remains limited. The major limitations to the use of PT based on their review were the lack of good clinical trials focused on the role of PT in POSA and the lack of objective measures of long term compliance. Other issues identified include patient discomfort with PT devices with resultant sleep disruption, which impacted long term compliance. They concluded that there was a need for technical improvement of PT devices and further innovative research.

\section{Methods}

An electronic search was done in the EMBASE database on November 26, 2016 using the key words "Positional AND Therapy AND Sleep AND Apnea". The search was from the time of the last review in 2012, until the date of the current search. We identified ten studies evaluating PT effectiveness and compliance. These studies were then stratified using the University of Oxford Level of Evidence for Evidence Based Medicine (Table I).

We also identified and discussed six studies that focused on improving the current practice of PT. Three of these studies proposed subclassification systems for POSA to guide the clinical use of PT while the others were studies done to validate tools being developed to obtain compliance data for PT. There was one study which demonstrated the cost effectiveness of incorporating PT into the OSA management algorithm when appropriate, compared to the use of Continuous Positive Airway Pressure therapy (CPAP) alone.

\section{Results}

\section{Positional Therapy Devices}

Positional therapy devices range from simple improvised devices mimicking the popular tennis ball technique to specially made apparatus, of which there are several varieties available. The US Food and Drug Administration (FDA) have cleared three of such devices for use in clinical practice. 
- A lightweight semi rigid wedge shaped device attached to an elastic belt and worn around the upper torso (Zzoma Positional Sleeper, Sleep Specialists, LLC, Abington, PA) used to prevent supine sleep in a study of 38 people with POSA by Permut et al. [8]. The device also normalized AHI to $<5 /$ hour in study participants.

- A battery powered neck-positioning device (Night Shift Sleep Positioner, Advanced Brain Monitoring, Carlsbad, CA) used to limit supine sleep in a study of 30 patients with POSA by Levendowski et al. [9]. The device minimized supine sleep by vibrating on detection of supine sleep. With the use of this device, $73 \%$ of study participants achieved an AHI of $<10$ /hour.

- A double incline triangular pillow (SONA Pillow, Kissimmee, Florida) used to promote persistent lateral positioning and downward positioning of the jaw during sleep in a study of 22 patients with OSA by Zuberi et al. [10]. Patients with mild to moderate OSA were successfully treated with the device with a reduction in snoring as well as AHI to $<5 /$ hour.

Other positional therapy devices have been studied and demonstrated efficacy in limiting supine sleep [11,12], but do not have FDA clearance.

\section{Overview of literature}

There were ten studies published in the English language between 2012 and 2016 evaluating the effectiveness of PT in POSA (Table 2).

\section{The Effectiveness of PT in the management of POSA}

Benoist et al. [13] examined the effect of PT in the management of residual POSA following upper airway surgery. They used a PT device which vibrated whenever the supine position was assumed. Twelve of thirty three $(37.5 \%)$ post operative patients treated with PT for 3 months showed a treatment response based on a follow up polysomnogram which demonstrated an overall reduction in AHI as well as a reduction in the Epworth Sleepiness Scale (ESS). The nonresponders as well had a reduction in supine sleep and better minimum oxygen saturations. Compliance with PT, measured as usage for $\geq 4$ hours a night for $\geq 5$ days of the week, was reported at $89 \%$.

Jackson et al. [14] randomized 86 patients to treatment with PT using a "tennis ball-like" device in addition to sleep hygiene advice vs. sleep hygiene advice alone, for a four week period. Sleep hygiene advice included exercise, weight loss and sleeping in the lateral position. At the end of four weeks, both groups underwent a follow up polysomnogram. The active group wore a positional device during the follow up polysomnogram while the control group did not. The study showed a significant reduction in supine sleep as well as in AHI in the active group versus the control group. There was, however, no significant reduction in daytime sleepiness, neuropsychological measures and overall quality of life.

Bidarian-Moniri et al. [15] assessed the effect of prone positioning on OSA. Thirty-two patients underwent a two night polygraphy. The first night was on a normal bed with optional positioning and a second night on a mattress and pillow for prone positioning (MPP). Seventeen of the twenty seven patients who completed the study were deemed to be responders and showed a significant reduction in mean AHI, oxygen desaturation index (ODI) and total supine sleep time. Twelve of the responders had POSA and five had non-POSA.

The same group also evaluated fourteen patients with mild to moderate OSA with two ambulatory polysomnograms done 4 weeks apart. The first was a baseline study done without any treatment, the second study was a treatment study with the MPP, carried out after the study participants had got accustomed to using the positioning device at home. The treatment study demonstrated a reduction in AHI and ODI, a reduction in supine time and an increase in prone time when compared to the baseline study. Ten of the patients achieved a 50\% reduction in their AHI to values $<10$ /hour [16].

In a retrospective study, DeVries et al. [17] conducted follow up polygrams (without electroencephalograms) on forty patients using PT after a period of twelve weeks and demonstrated treatment success in twenty seven of them based on significant reductions in AHI and improved oxygen saturations. The PT devices were either commercial waistbands or improvised by patients, both mimicking the tennis ball technique. Despite the demonstrated effectiveness of PT, patient usage diminished and long-term compliance was extremely poor. The majority of the patients, 26 of 40 patients were no longer using PT at follow up several months later. 
Van Maanen et al. [4] limited supine sleep in a study of 145 patients with POSA using a lightweight device with an accelerometer, which vibrated on detecting supine positioning. The device was capable of storing data on sleep position. One hundred and six participants completed the study and showed a sustained reduction in supine sleep at 6 months with near total avoidance of supine sleep. This was based on data obtained from the device. The supine sleep median percentage was $2 \%, 2 \%$ and $3 \%$ of total sleep time at 1 month, 3 months and 6 months respectively. Compliance defined as usage for $>4$ hours per night was measured at $64.4 \%$. However, if drop outs are taken into account, compliance was only $46.9 \%$. Measures of subjective sleepiness and sleep related quality of life also improved based on completion of the ESS, Functional Outcomes of Sleep Questionnaire (FOSQ), Pittsburgh Sleep Quality index questionnaires at baseline, 1 month, 3 months and 6 months into the study.

Levendowski et al. [9] assessed the efficacy of a neck worn PT device, which vibrated on supine positioning, in a study of 30 patients. Their results showed significant reductions in AHI, improvements in oxygen saturation, reductions in arousal/improved sleep continuity based on comparison of baseline and follow up polysomnograms performed after at least 4 weeks of therapy. Post treatment questionnaires showed a significant improvement in depression scores when compared to baseline questionnaires.

Van Maanen et al. [1] studied 31 patients with POSA, treated with a vibrational PT device and demonstrated a significant reduction in median percentage supine sleep time and median AHI. Fifteen of these achieved an optimal AHI of $<5 /$ hour. There was no significant change in sleep efficiency but sleep related quality of life was improved based on ESS and FOSQ questionnaires completed by the study participants. Short term compliance with PT, defined as usage every night for at least 4 hours per night was $92.7 \%$ at one month.

In another study by Van Maanen et al. [18], evaluating thirty POSA patients treated using a neck-worn vibrational PT device, the study participants had a significant reduction in AHI. Seven patients showed optimal reduction in AHI to $<$ 5/hour. Based on these findings, they proposed that PT could be a stand alone treatment in some mild to moderate POSA patients and as an adjunct in more severe cases.

Heinzer et al. [19] studied sixteen patients with POSA who were treated with PT using a "tennis ball-like" device over 3 months. Comparison of treatment polysomnographies with PT performed at 0 and 3 months, demonstrated sustained efficacy of PT with significant reductions in AHI, oxygen desaturation index and supine sleep time. There was also a significant decrease in ESS measured at 0 and 3 months. Compliance at 3 months was objectively measured using an actigraphic monitor incorporated into the positional device at an average of $73.7 \%$ usage for $8 \pm 2$ hours per night.

\section{$\underline{\text { Subclassification of POSA }}$}

There are currently no universal criteria for the diagnosis of POSA although several definitions have been utilized in literature [20]. This is a major barrier to the development of clear guidelines for the management of POSA.

Cartwright identified the clinical importance of differentiating between positional and non-positional OSA in 1984 [21]. She defined POSA using an arbitrary cut off point of a difference of $\geq 50 \%$ in apnea index between supine and lateral sleep positions.

In 1998, Markund et al. [22] defined POSA as supine AHI $\geq 10$ and lateral AHI $<10 /$ hour.

Mador et al. [23] and Permut et al. [8] proposed that in addition to the $\geq 50 \%$ decrease in AHI from supine to non supine positions as defined by Cartwright, the non supine AHI should be $<5 /$ hour to qualify as POSA.

Bignold et al. [11] excluded mild OSA from their definition of POSA. They defined POSA as an overall AHI $\geq 15$ events per hour, supine to non supine AHI of $\geq 2: 1, \geq 20$ minutes of sleep spent in supine and non supine postures and a non supine AHI $<15$ events per hour.

More recently, Frank et al. [20] proposed the Amsterdam Positional OSA Classification (APOC), which essentially modified Cartwright's classification. Their recommendations were based on a consensus standard from experts in the field.

The APOC suggests the following criteria for the diagnosis of POSA:

- Patients should be diagnosed with OSA according to the American Academy of Sleep Medicine (AASM) criteria 
- $\quad$ Patients spend greater than $10 \%$ of their total sleep time (TST) in both their best (BSP) and worst sleeping positions (WSP)

- $\quad$ They suggest subclassifying POSA into three groups

APOC I - AHI in BSP $<5$ events per hour

APOC II - Lower OSA severity in BSP than their overall OSA category

APOC III - Overall $\mathrm{AHI} \geq 40$ and $\mathrm{AHI}$ in $\mathrm{BSP}$ is $\geq 25 \%$ reduced compared to the overall AHI

The APOC system differentiates OSA patients into true positional, the non-positional patient and the multifactorial patient (OSA severity partly influenced by position). Using the APOC criteria, the prevalence of POSA was $\sim 55 \%$ in their OSA group. The APOC I group can potentially be optimally treated with PT as a stand alone therapy; the use of PT in APOC II and III would be as an adjunct or salvage therapy. The APOC was shown to have a better sensitivity (98\%), specificity $(88 \%)$, positive predictive value $(89 \%)$ and negative predictive value $(98 \%)$ in detecting POSA when compared to other POSA classification methods [20].

The same group this time with Ravesloot as the lead author proceeded to compare diagnosis of POSA using APOC vs Cartwright criteria and demonstrated that more POSA cases were diagnosed, particularly in those with mild OSA using APOC [24]. Most of the mild OSA patients with POSA were APOC I (true positional) and could be treated with PT only. This group is less likely to be symptomatic and hence less likely to be compliant with CPAP so PT would be a suitable and cost effective treatment in this subgroup.

Kim et al subclassified patients with POSA based on a modified Cartwright classification (excluding patients who spent less than 30 minutes each in the supine and non supine positions) into 2 groups and concluded that clinical features of both groups were different and subtyping POSA patients would help to guide treatment [25]. They proposed two subclasses:

- $\quad$ Supine isolated OSA (siOSA): non-supine AHI $<5$ events per hour $(27 \%)$

- $\quad$ Supine predominant (spOSA): non-supine AHI $>5$ events per hour $(73 \%)$

Lee et al also subclassified POSA based on the Cartwright classification into 3 subtypes based on their non supine AHI and noted that the three subgroups had different clinical characteristics. They also felt that subtyping POSA may help guide treatment options [26].

- $\quad$ Subtype I - non-supine AHI $<5$ events per hour (53\%)

- $\quad$ Subtype 2 - non-supine AHI $>5$ but $<15$ events per hour $(28 \%)$

- $\quad$ Subtype 3 - non-supine AHI $\geq 15$ events per hour (19\%)

There is no clear evidence at the present time to define the clinical role of subclassifying POSA. Further studies are needed to assess the usefulness of POSA subclasses in the management of POSA.

\section{Compliance monitoring in PT}

There have been studies evaluating methods to assess compliance with PT. The devices were able to monitor position and therefore record sleep positioning during nights of use and hence give objective compliance reports on a day-to-day basis.

Van Maanen et al. [4] validated the accuracy of a vibratory supine avoidance device in measuring compliance. The device had an in built position sensor and was able to measure hours of use. Compliance was measured using the same criteria for CPAP compliance of 4 hours of usage per night. Objective measurement of compliance by the device was $71.2 \%$ and corresponded with subjective data obtained from self-reported online questionnaires, measured at $74.4 \%$.

Another device using an accelerometer and a microphone was able to detect key sleep parameters including sleep position, snoring, sleep versus wake. It also stored usage data and reports could be generated from a web portal. Patients were responsible for downloading their usage data from the portal, as the memory of the device was limited to six nights for detailed reports. However, summarized reports were available for up to 12 months. On the other hand, substantial drop out of patients was found. The accuracy of the device in detecting supine sleep and in detecting sleep/wake via actigraphy was validated by Levendowski et al. [9] by comparing the data from the device with video recordings and polysomnogram findings.

In a preliminary communication of Omobomi et al. [27], the data from a portable wireless motion sensor chip was compared to manually scored data based on video recordings during polysomnography. There was a significant correlation between the two data sets, demonstrating accuracy of the chip in measuring position as well as time of use. There are ongoing efforts to incorporate the chip into a commercially available positional therapy device. 
There was one abstract published by Ramos et al. [28] on the cost-effectiveness of PT. In that analysis, PT when used in the appropriate settings is proven to be cost effective. They demonstrated a cost saving by incorporating positional therapy into the treatment algorithm for OSA compared to using CPAP alone. The study consisted of 42 patients with OSA, 6 patients opted for weight management and one for an oral appliance. Twelve of the remaining 35 patients had POSA and were treated with PT and 23 were treated with CPAP. Average cost per patient for PT was $\$ 289.95$ whilst average cost per patient for CPAP was $\$ 962.49$. The use of PT in the 12 patients with POSA yielded savings of $24 \%$ when compared to using CPAP for all 35 patients.

\section{Discussion}

Studies on PT in the management of POSA since the last review by Ravesloot et al. [2] continue to document efficacy in decreasing AHI and supine sleep. However, the vast majority of studies are small case series and cohort studies. Large good quality randomized controlled trials with long term follow up are lacking. This poses a limitation in providing a good evidence base for the routine use of PT in clinical practice.

The efficacy of PT is primarily measured by reduction in supine sleep and AHI. Optimal treatment of OSA is currently defined as AHI $<5 /$ hour. Some studies on PT efficacy achieve a significant reduction in supine sleep and AHI, but treatment AHI remains $>5 /$ hour and these are still regarded as successful treatments. It is not clear whether some PT techniques are superior to others in minimizing supine sleep and optimizing reductions in AHI.

Measurements of the effect of PT on secondary outcomes like daytime sleepiness, neuropsychological outcomes and sleep related quality of life have yielded inconsistent results. Bearing in mind that these studies utilize various PT devices, it is difficult to generalize the results. There are various mechanisms by which PT devices limit supine sleep. Some devices make it difficult/uncomfortable to assume the supine position whilst others vibrate when supine sleep is detected to alert patients to assume a non supine position. The vibratory PT devices are arguably more comfortable than the PT devices that mimic the tennis ball technique, hence secondary outcomes may vary. PT devices with similar mechanisms of action may also vary in degree of comfort and tolerability.

Another potential limitation in creating guidelines for routine use in POSA is that there is no universal definition for POSA. The aforementioned studies have utilized various definitions of POSA. There are at least 4 different definitions of POSA detailed in this review.

The proposed subclassification systems for POSA are largely based off of Cartwright's original definition of POSA, with slight modifications in some cases. More studies are needed to assess the clinical role of subclassifying POSA. A consensus on a universal subclassification system will also be beneficial if there is indeed a clinical benefit. Much of the push for subtyping POSA is towards developing targeted clinical guidelines for incorporating PT into the OSA management algorithm. It may help determine in which patients PT will be effective as stand-alone therapy vs. adjunctive therapy

Since the last review, there has been further innovative research geared towards development and validation of compliance measurement tools for PT. To our knowledge, not all of these tools are commercially available at the present time for clinical use. One commercially available FDA cleared device has the capability to record hours of use and time spent in supine sleep. The major limitation identified with some of the described tools is the reliance on patients to manually upload their compliance data. Unfortunately, while PT compliance tools may detect snoring by the use of microphones, they do not have a means to detect residual apneas or hypopneas. Their inability to measure residual AHI means they do not provide data to confirm continued effectiveness of PT in limiting respiratory events with long term use.

Compliance with PT has no defined target criteria and PT compliance described in some of the identified studies is often measured using CPAP criteria or unique definitions as specified by the authors. However, it remains unclear how many hours of PT use per night and what percentage of nights PT needs to be used to achieve short and long term clinical benefits.

In the short term, PT appears to be cost effective when compared to CPAP. However, in the absence of data on the continued effectiveness of PT in the long term and the durability of PT devices, it is difficult to conclude whether PT is cost effective in the long run. CPAP is perceived to be durable and effective for up to 5 years bearing in mind that it is associated with ongoing maintenance costs; it is unclear how many PT device replacements will be needed in the same 
time frame to maintain effectiveness whilst also accounting for wear and tear. Further longitudinal studies are needed to assess long term costs of PT.

\section{Conclusions}

Positional therapy in its various forms is proven to be an effective therapy for management of POSA.

The routine use of PT is limited by several factors including the lack of a universal definition for POSA and the lack of specific clinical guidelines for the use of PT. Subtyping POSA patients may help create clearer practice guidelines for the use of PT and promote individualized care for POSA patients by determining who will benefit from PT as a standalone treatment or as adjunct therapy. There is a need for good quality clinical trials to further strengthen the evidence base for PT use in POSA.

Objective measurement of compliance with PT is an ongoing process and its successful implementation and easy availability will likely make PT use more favorable in the future. The inability to continuously monitor sustained effectiveness in limiting respiratory events may make PT compliance measurements remain inferior to CPAP compliance measurements.

It appears to be cost effective in the short term to incorporate PT into the OSA treatment algorithm, but it will be useful to know the long term running costs of PT to make a more accurate judgement. Despite new innovation and progress made in the field of PT since the last review, there still remains ample room for further innovative and clinical research into PT as well as POSA. 
Abbreviations

AHI - Apnea Hypopnea Index

APOC - Amsterdam Positional OSA Classification

BSP - Best sleeping position

CPAP - Continuous Positive Airway Pressure

ESS - Epworth Sleepiness Scale

FOSQ - Functional Outcomes of Sleep Questionnaire

MAD - Mandibular Advancement Devices

MPP - Mattress and pillow for prone positioning

ODI - Oxygen Desaturation Index

OSA - Obstructive Sleep Apnea

POSA - Positional Obstructive Sleep Apnea

PT - Positional Therapy

siOSA - supine isolated OSA

spOSA - supine predominant OSA

TST - Total sleep time

WSP - Worst sleeping position 


\section{References}

1. Van Maanen JP, Meester KAW, Dun LN, Koutsourelakis I, Witte BI, Laman DM, Hilgevoord AAJ, de Vries N (2013) The sleep position trainer: A new treatment for positional obstructive sleep apnea. Sleep Breath 17:771779

2. Jafari B, Roux F (2012) Non-positive airway pressure therapy for obstructive sleep apnea. Current Respiratory Care Reports 1:111-122

3. Rotenberg BW, Muriariu D, Pang KP (2016) Trends in CPAP Adherence over twenty years of data collection: a flattened curve. J Otolaryngol Head Neck Surg 45:43

4. Van Maanen JP, De Vries N (2014) Long-term effectiveness and compliance of positional therapy with the sleep position trainer in the treatment of positional obstructive sleep apnea syndrome. Sleep 37:1209-1215

5. Ravesloot, MJL, Van Maanen JP, Dun L, De Vries N (2013) The undervalued potential of positional therapy in position-dependent snoring and obstructive sleep apnea - a review of the literature. Sleep Breath 17:39-49

6. Cartwright RD, Diaz F, Lloyd S (1991) The effect of sleep posture and sleep stage on apnea frequency. Sleep 14:351-353

7. Calik W (2016) Treatments for Obstructive Sleep Apnea. J Clin Outcomes Manag 23: 181-192

8. Permut I, Diaz-Abad M, Chatila W, Crocetti J, Gaughan JP, D’Alonzo GE, Krachman SL (2010) Comparison of positional therapy to CPAP in patients with positional obstructive sleep apnea. J Clin Sleep Med 6:238-243

9. Levendowski DJ, Seagraves S, Popovic D, Westbrook PR (2014) Assessment of a neck-based treatment and monitoring device for positional obstructive sleep apnea. J Clin Sleep Med 10:863-871

10. Zuberi NA, Rekab K, Nguyen HV (2004) Sleep apnea avoidance pillow effects on obstructive sleep apnea syndrome and snoring. Sleep Breath 8: 201-207

11. Bignold JJ, Mercer JD, Antic NA, McEvoy RD, Catcheside PG (2011) Accurate position monitoring and improved supine-dependent obstructive sleep apnea with a new position recording and supine avoidance device. $\mathrm{J}$ Clin Sleep Med 7: 376-383

12. Matthews L, Fortier N (2013) The Rematee Bumper Belt ${ }^{\circledR}$ positional therapy device for snoring and obstructive sleep apnea: Positional effectiveness in healthy subjects. Can J Respir Ther 49:11-14.

13. Benoist LBL, Verhagen M, Torensma B, van Maanen JP, de Vries N (2016) Positional therapy in patients with residual positional obstructive sleep apnea after upper airway surgery. Sleep Breath. doi:10.1007/s11325-0161397-x

14. Jackson M, Collins A, Berlowitz D, Howard M, O’Donoghue F, Barnes M (2015) Efficacy of sleep position modification to treat positional obstructive sleep apnea. Sleep Medicine 16:545-552

15. Bidarian-Moniri A, Nilsson M, Rasmusson L, Attia J, Ejnell H (2015) The effect of the prone sleeping position on obstructive sleep apnea. Acta Oto-Laryngologica 135:79-84

16. Bidarian-Moniri A, Nilsson M, Attia J, Ejnell H (2015) Mattress and pillow for prone positioning for treatment of obstructive sleep apnea. Acta Oto-Laryngologica 135:271-276

17. De Vries GE, Hoekema A, Doff MHJ, Kerstjens HAM, Meijer PM, Van Der Hoeven JH, Wijkstra PJ (2015) Usage of positional therapy in adults with obstructive sleep apnea. J Clin Sleep Med 11:131-137

18. Van Maanen JP, Richard W, Van Kesteren ER, Ravesloot MJL, Laman DM, Hilgevoord AAJ, De Vries N (2012) Evaluation of a new simple treatment for positional sleep apnea patients. Journal of Sleep Research 21:322-329

19. Heinzer RC, Pellaton C, Rey V, Rossetti AO, Lecciso G, Haba-Rubio J, Tafti M, Lavigne G (2012) Positional therapy for obstructive sleep apnea: An objective measurement of patient's usage and efficacy at home. Sleep Medicine 13:425-428

20. Frank MH, Ravesloot MJL, van Maanen JP, Verhagen E, de Lange J, de Vries N (2015) Positional OSA part 1: towards a clinical classification system for position dependent sleep apnea. Sleep Breath 19:473-480

21. Cartwright RD (1984) Effect of sleep position on sleep apnea severity. Sleep 7:110-114

22. Marklund M, Persson M, Franklin KA (1998) Treatment success with a mandibular advancement device is related to supine-dependent sleep apnea. Chest 114:1630-1635

23. Mador MJ, Kufel TJ, Magalang UJ, Rajesh SK, Watwe V, Grant BJ (2005) Prevalence of positional sleep apnea in patients undergoing polysomnography. Chest 128:2130-2137

24. Ravesloot MJL, Frank MH, van Maanen JP, Verhagen EA, de Lange J, de Vries N (2016) Positional OSA part 2: retrospective cohort analysis with a new classification system (APOC). Sleep Breath 20: 881-888

25. Kim KT, Cho YW, Kim DE, Hwang SH, Song ML, Motamedi GK (2016) Two subtypes of positional obstructive sleep apnea: Supine-predominant and supine-isolated. Clinical Neurophysiology 127:565-570)

26. Lee S-A, Paek J-H, Chung Y-S, Kim WS (2016) Clinical features in patients with positional obstructive sleep apnea according to its subtypes. Sleep Breath. https://doi.org/10.1007/s11325-016-1379-z

27. Omobomi O, Krahnke JS, Ramos FL, Chatila W, Shariff T, D'Alonzo GE, Jaffe F, Vega M, Krachman SL (2015) Accuracy of a new wireless portable monitoring chip to determine body position and time of use during sleep. Sleep 38 (A424-) 
28. Ramos FL, Chatila W, Shariff T, Jaffe F, D'Alonzo GE, Vega ME, Krachman SL (2015)

Cost effectiveness of incorporating positional therapy into a treatment algorithm for obstructive sleep apnea. Sleep 38 (A442-)

Table I : Oxford Center for Evidence-based Medicine Level of Evidence

\begin{tabular}{|l|l|}
\hline Level of Evidence & \multicolumn{1}{|c|}{ Therapy } \\
\hline $1 \mathrm{a}$ & Systematic review of randomized control trials \\
\hline $1 \mathrm{~b}$ & Individual randomized control trials \\
\hline $1 \mathrm{c}$ & All or none \\
\hline $2 \mathrm{a}$ & Systematic review of cohort studies \\
\hline $2 \mathrm{~b}$ & Individual cohort study, low quality randomized control studies \\
\hline $2 \mathrm{c}$ & Outcomes Research \\
\hline $3 \mathrm{a}$ & Systematic review of case control studies \\
\hline $3 \mathrm{~b}$ & Individual case control study \\
\hline 4 & Case series, poor quality cohort and case control studies \\
\hline 5 & Expert opinion \\
\hline
\end{tabular}


Table II : Evidence Table

\begin{tabular}{|c|c|c|c|c|c|c|c|c|c|c|c|c|c|c|c|c|c|}
\hline & Year & Design & LOE & No & $\begin{array}{l}\mathrm{BMI} \\
\mathrm{Kg} / \\
\mathrm{m}^{2}\end{array}$ & Device & AHI & $\begin{array}{l}\mathrm{AHI} \\
(+\mathrm{PT})\end{array}$ & $\begin{array}{l}\text { Supine } \\
\text { TST } \\
\%\end{array}$ & $\begin{array}{l}\text { Supine } \\
\text { TST } \\
(+\mathrm{PT}) \\
\%\end{array}$ & $\begin{array}{l}\text { Sleep } \\
\text { Efficiency } \\
\%\end{array}$ & $\begin{array}{l}\text { Sleep } \\
\text { Efficiency } \\
(+\mathrm{PT}) \\
\%\end{array}$ & ESS & $\begin{array}{l}\text { ESS } \\
(+\mathrm{PT})\end{array}$ & $\begin{array}{l}\text { Minimum } \\
\text { Oxygen } \\
\text { Saturation } \\
\%\end{array}$ & $\begin{array}{l}\text { Minimum } \\
\text { Oxygen } \\
\text { Saturation } \\
(+\mathrm{PT}) \\
\% \\
\end{array}$ & $\begin{array}{l}\text { Site } \\
+ \\
\text { FU }\end{array}$ \\
\hline $\begin{array}{l}\text { Benoist L } \\
\text { et al }\end{array}$ & 2016 & $\begin{array}{l}\text { Prospective } \\
\text { Cohort } \\
\text { (post op) }\end{array}$ & 4 & $\begin{array}{l}32 / \\
33\end{array}$ & $\begin{array}{l}27.9 \\
+/- \\
2.8\end{array}$ & $\begin{array}{l}\text { Sleep Position } \\
\text { Trainer }\end{array}$ & $18.3^{\mathrm{b}}$ & $12.5^{\mathrm{b}}$ & $40.1^{\mathrm{b}}$ & $7.4^{\mathrm{b}}$ & $90.8^{\mathrm{b}}$ & $89.5^{\mathrm{b}}$ & $10^{b}$ & $7^{b}$ & $85.5^{\mathrm{b}}$ & $88^{\mathrm{b}}$ & $\begin{array}{l}\text { The Netherlands } \\
3 \text { months }\end{array}$ \\
\hline $\begin{array}{l}\text { Jackson M } \\
\text { et al } * * *\end{array}$ & 2015 & $\begin{array}{l}\text { RCT } \\
\text { Case control }\end{array}$ & $2 b$ & $\begin{array}{l}46 / \\
86 \\
* * *\end{array}$ & $30^{\mathrm{a}}$ & $\begin{array}{l}\text { Tennis Ball } \\
\text { SPM Device }\end{array}$ & $20.1^{\mathrm{a}}$ & $10.8^{\mathrm{a}}$ & $130.9^{\mathrm{a}, \mathrm{c}}$ & $28.4^{\mathrm{a}, \mathrm{c}}$ & $76.3^{\mathrm{a}}$ & $75.5^{\mathrm{a}}$ & $9.9^{\mathrm{a}}$ & $8.1^{\mathrm{a}}$ & $87.9^{\mathrm{a}}$ & $89.8^{\mathrm{a}}$ & $\begin{array}{l}\text { Australia } \\
4 \text { weeks }\end{array}$ \\
\hline $\begin{array}{l}\text { Bidarian MA et } \\
\text { al }\end{array}$ & 2015 & Case series & 4 & $\begin{array}{l}27 / \\
32\end{array}$ & $28^{\mathrm{a}}$ & $\begin{array}{l}\text { Mattress \& } \\
\text { pillow for } \\
\text { prone } \\
\text { positioning } \\
\text { (MPP) }\end{array}$ & $23^{\mathrm{b}}$ & $7^{b}$ & $142^{\mathrm{b,c}}$ & $<1^{\mathrm{b}, \mathrm{c}}$ & NA & NA & NA & NA & NA & NA & $\begin{array}{l}\text { Sweden } \\
2 \text { days }\end{array}$ \\
\hline $\begin{array}{l}\text { Bidarian MA et } \\
\text { al }\end{array}$ & 2015 & Cohort & 4 & 14 & $26^{\mathrm{a}}$ & MPP & $26^{\mathrm{a}}$ & $8^{a}$ & $128^{\mathrm{a}, \mathrm{c}}$ & $10^{a, c}$ & $79^{\mathrm{a}}$ & $74^{\mathrm{a}}$ & $12^{\mathrm{a}}$ & $9^{\mathrm{a}}$ & $80^{\mathrm{a}}$ & $87^{\mathrm{a}}$ & $\begin{array}{l}\text { Sweden } \\
4 \text { weeks }\end{array}$ \\
\hline $\begin{array}{l}\text { De Vries GE et } \\
\text { al }\end{array}$ & 2015 & $\begin{array}{l}\text { Retrospective } \\
\text { observational }\end{array}$ & 4 & $\begin{array}{l}40 / \\
53\end{array}$ & $\begin{array}{l}28 \\
+1 \\
4 . \overline{1}\end{array}$ & $\begin{array}{l}\text { Werkmeister } \\
\text { SnurkStop/ } \\
\text { Tennis ball } \\
\text { mimics }\end{array}$ & $14.5^{\mathrm{b}}$ & $5.9^{\mathrm{b}}$ & $155.3^{\mathrm{b}, \mathrm{c}}$ & $33.5^{\mathrm{b}, \mathrm{c}}$ & NA & NA & $\begin{array}{l}12.2 \\
+1 \\
5 . \overline{4}\end{array}$ & $\begin{array}{l}10.2+/- \\
5.5\end{array}$ & $86^{\mathrm{b}}$ & $87^{b}$ & $\begin{array}{l}\text { The Netherlands } \\
12 \text { weeks }\end{array}$ \\
\hline $\begin{array}{l}\text { Van Maanen JP } \\
\text { et al }\end{array}$ & 2014 & $\begin{array}{l}\text { Prospective } \\
\text { multi-center } \\
\text { cohort }\end{array}$ & 4 & $\begin{array}{l}106 / \\
145\end{array}$ & $27^{b}$ & $\begin{array}{l}\text { Sleep Position } \\
\text { Trainer }\end{array}$ & $11.5^{\mathrm{b}}$ & NA & $21^{\mathrm{b}}$ & $3^{b}$ & NA & NA & $11^{\mathrm{b}}$ & $8^{\mathrm{b}}$ & NA & NA & $\begin{array}{l}\text { The Netherlands } \\
6 \text { months }\end{array}$ \\
\hline $\begin{array}{l}\text { Levendowski } \\
\text { DJ et al }\end{array}$ & 2014 & $\begin{array}{l}\text { Prospective } \\
\text { Cohort }\end{array}$ & 4 & $\begin{array}{l}30 / \\
36\end{array}$ & $\begin{array}{l}28+/- \\
3.4\end{array}$ & $\begin{array}{l}\text { Night Shift } \\
\text { Sleep } \\
\text { Positioner }\end{array}$ & $\begin{array}{l}24.7 \\
+/- \\
14.7\end{array}$ & $\begin{array}{l}7.5 \\
+/- \\
7.7\end{array}$ & $\begin{array}{l}46.4+/- \\
12.7\end{array}$ & $\begin{array}{l}2.2 \\
+/- \\
6.1\end{array}$ & $\begin{array}{l}80.9 \\
+/- \\
11.9\end{array}$ & $\begin{array}{l}85.1 \\
+/- \\
7.6\end{array}$ & $\begin{array}{l}11.3 \\
+/- \\
4.6\end{array}$ & $\begin{array}{l}9.5 \\
+/- \\
4.6\end{array}$ & NA & NA & $\begin{array}{l}\text { California } \\
4 \text { weeks }\end{array}$ \\
\hline $\begin{array}{l}\text { Van Maanen JP } \\
\text { et al }\end{array}$ & 2013 & $\begin{array}{l}\text { Prospective } \\
\text { Cohort }\end{array}$ & 4 & $\begin{array}{l}31 / 3 \\
6\end{array}$ & $\begin{array}{l}27 \\
+/- \\
3.7\end{array}$ & $\begin{array}{l}\text { Sleep Position } \\
\text { Trainer }\end{array}$ & $16.4^{b}$ & $5.2^{\mathrm{b}}$ & $49.9^{b}$ & $0^{\mathrm{b}}$ & $89.1^{\mathrm{b}}$ & $89.4^{\mathrm{b}}$ & $11^{\mathrm{b}}$ & $9^{b}$ & $84.5+/-4.1$ & $88.4+/-3.6$ & $\begin{array}{l}\text { The Netherlands } \\
1 \text { month }\end{array}$ \\
\hline $\begin{array}{l}\text { Van Maanen JP } \\
\text { et al }\end{array}$ & 2012 & $\begin{array}{l}\text { Prospective } \\
\text { Cohort }\end{array}$ & 4 & 30 & $\begin{array}{l}27.7+1 \\
-3.6\end{array}$ & $\begin{array}{l}\text { Sleep Position } \\
\text { Trainer }\end{array}$ & $\begin{array}{l}27.7 \\
+1 \\
2.4\end{array}$ & $\begin{array}{l}12.8 \\
+/ \_2.2\end{array}$ & $\begin{array}{l}40+1 \\
3.5\end{array}$ & $\begin{array}{l}19 \\
+1 \\
4.1\end{array}$ & $91.9+/-1.4$ & $\begin{array}{l}88.3+/- \\
1.8\end{array}$ & NA & NA & NA & NA & $\begin{array}{l}\text { The Netherlands } \\
18 \text { months }\end{array}$ \\
\hline $\begin{array}{l}\text { Heinzer RC et } \\
\text { al }\end{array}$ & 2012 & $\begin{array}{l}\text { Prospective } \\
\text { Cohort }\end{array}$ & 4 & 16 & $\begin{array}{l}25.4 \\
+/- \\
4.1\end{array}$ & $\begin{array}{l}\text { Tennis ball } \\
\text { derivative }\end{array}$ & $\begin{array}{l}26.7 \\
+/- \\
17.5\end{array}$ & $\begin{array}{l}6.0+/- \\
3.4\end{array}$ & $\begin{array}{l}42.8+/- \\
26.2\end{array}$ & $\begin{array}{l}5.8 \\
+/-7.2\end{array}$ & NA & NA & $\begin{array}{l}9.4 \\
+/- \\
4.5\end{array}$ & $\begin{array}{l}6.6+/ \\
4.7^{+}\end{array}$ & $\begin{array}{l}84.7 \\
+/-3.8\end{array}$ & $\begin{array}{l}87.3+/- \\
4.3\end{array}$ & $\begin{array}{l}\text { Switzerland } \\
3 \text { months }\end{array}$ \\
\hline
\end{tabular}


+ PT: With Positional Therapy

a: Mean

b: Median

c: Minutes

AHI: Apnea hypopnea index

ESS: Epworth sleepiness scale

FU: Follow up period

LOE: Level of evidence

NA: Not analyzed

SPM: Sleep position modification

TST: Total sleep time

Data are presented as mean + - SD unless otherwise indicated

***Case control studies: data included for cases only, control data excluded 